\title{
Design and development of Schiff's base (SB)-modified polylactic acid (PLA) antimicrobial film for packaging applications
}

\section{Sundar Natesan ${ }^{1} \cdot$ Johan Stanley Samuel ${ }^{1} \cdot$ Ananda Kumar Srinivasan $^{1} \mathbb{D}$}

Received: 10 October 2020 / Revised: 31 March 2021 / Accepted: 13 April 2021 /

Published online: 21 May 2021

(C) The Author(s), under exclusive licence to Springer-Verlag GmbH Germany, part of Springer Nature 2021

\begin{abstract}
SB compounds were synthesized from (para, ortho, meta)-phenylenediamine as a cross-linking agent through vanillin. The chemical structure of the formed SB complexes is confirmed by FT-IR spectroscopy. Among the three complexes, para-phenylenediamine (p-SB), possessing a stable resonance structure with the lowest steric repulsion, was obtained in the highest yield of $87 \%$. Hence, the present work focused on reducing the brittle behavior and improving the antimicrobial activity of PLA by reacting it with p-SB. FT-IR investigation revealed the existence of an intermolecular hydrogen bonding between PLA and SB, which led to an increased toughness in the PLA-p-SB complex. This is further confirmed through SEM analysis. The tensile and contact angle measurements determined an improvement in mechanical properties and hydrophobic nature of the PLA-p-SB film. DSC results demonstrated an increase in flexibility, which indicated a $10{ }^{\circ} \mathrm{C}$ reduction in glass transition temperature $\left(T_{\mathrm{g}}\right)$ of PLA-p-SB films. The antimicrobial activity of the PLA-p-SB films had a maximum of $15 \mathrm{~mm}$ zone of inhibition, which was found to be more effective than the neat PLA film. PLA-p-SB coating on Kraft paper showed improved mechanical and barrier properties than neat PLA coatings and could be tried as a possible replacement for conventional synthetic packaging materials.
\end{abstract}

Ananda Kumar Srinivasan srinivanand@gmail.com

1 Department of Chemistry, College of Engineering Guindy, Anna University, Chennai 600025, India 


\section{Graphic abstract}

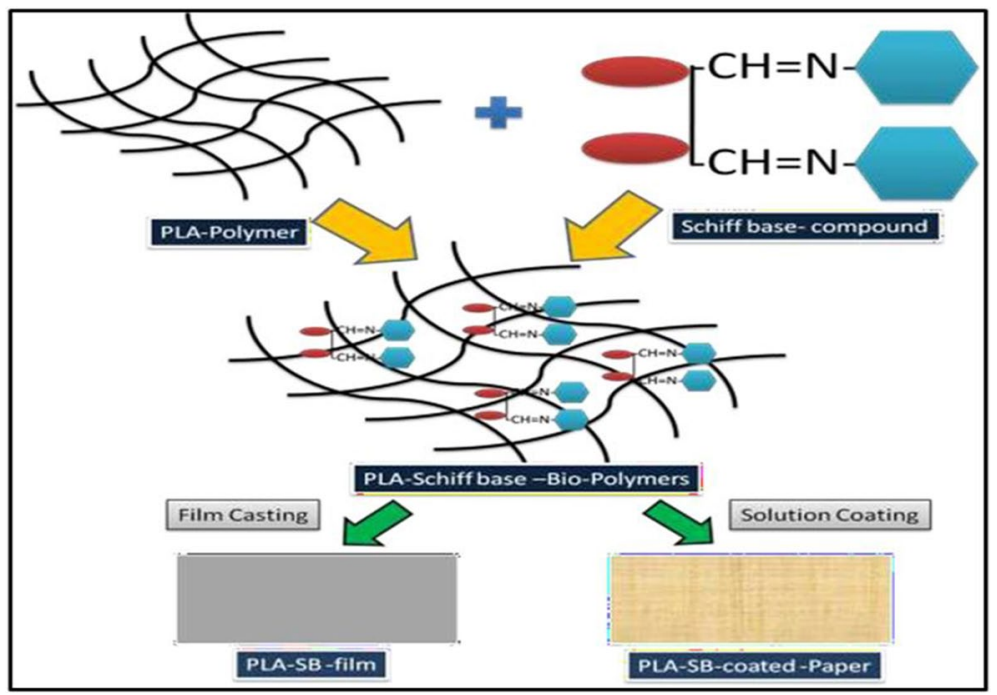

Keywords Schiff's base · Antibacterial · PLA-p-SB film · Kraft paper coatings · Packaging

\section{Introduction}

The COVID-19 has made a considerable impact in the recent past on the packaging industry, besides having caused a severe concern over the health and safety of products. These effects may probably persist for long till the pandemic subsides. Rick lingle [1] reported that nearly $40 \%$ of people in the USA use household disinfectants to clean the products. Consequently, many companies have now switched over to the manufacture of eco-friendly alternatives and antimicrobial packaging systems. PLA usage in coatings and packaging has been increasing progressively in the last few years due to its bio-based and degradable nature. At the same time, it poses different challenges in packaging industries due to its limited mechanical, barrier, and antimicrobial properties. Hence, modification of PLA by blending it with other polymers or additives like antibacterial agents, plasticizers, and antioxidants is mandatory to meet the end-user needs and demands [2].

SB is an organic compound containing an azomethine group used in food packaging, coloring agent to leathers, and anti-corrosion agent for metals. It also exhibits excellent resistance against light and acidic gases [3]. On the other side, SBs play a vital role in the medical and pharmaceutical fields due to their remarkable biological activities like antimicrobial, antifungal, anti-viral, antibacterial, anti-tumor, antiinflammatory, anti-malarial, anti-pyretic activity, etc. [4]. The molecular features of vanillin, such as hydrophobicity from an aromatic ring, reactivity from carbonyl 
group, and the ability to form the multi-molecular structure through hydrogen bonding, make it a suitable cross-linking agent for SB's. E.A. Soliman et al. [5] reported that SB's of Zein-based films showed significance in improving flexibility, solubility, and antimicrobial activity and found their potential applications in the packaging and biomedical field. Rarima et al. [6] obtained biodegradable microporous polylactide film using zinc oxide and SB for biocompatible applications, typically for wound dressing. However, there appears to be a limited amount of work done to link SB with PLA. Hence, an attempt has been made in the present work to synthesize SB complexes as a cross-linking agent via vanillin to link p-SB with the PLA matrix to improve its mechanical, hydrophobic, and antimicrobial properties that are ideally needed for industrial applications. Finally, PLA-p-SB was coated onto Kraft paper and characterized by various testing methods to find its suitability as antimicrobial packaging material, which would directly impact consumer health through safer packaging [7]. We consider the above aspects of our work as novel.

\section{Materials and methods}

\section{Materials}

PLA Ingeo $^{\mathrm{TM}}$ (PLA-3052 D) was procured in granule form from Nature Works, USA, with specifications (SG: $1.24 \mathrm{~kg} / \mathrm{m}^{3}, \mathrm{M}: 154.8 \mathrm{~kg} / \mathrm{Mol}$ ). Dichloromethane (DCM), vanillin, and (para, ortho, meta)-phenylenediamine analytical grade supplied by Merck \& Co.

\section{Synthesis of SB complexes}

Vanillin-based SB was synthesized by reacting with (para, ortho, meta)-phenylenediamine and maintaining the ratio of $2: 1$ in ethanol solution medium. The reaction was carried out for about $6 \mathrm{~h}$ at $50{ }^{\circ} \mathrm{C}$ under a nitrogen atmosphere. The reacted mixture was cooled to room temperature, and the SB compound was washed with water, followed by absolute ethanol, and DCM solvents to remove the un-reacted portions and moisture. The re-crystallization process of SB compound was carried out using absolute ethanol solvent and the recrystallized product was stored in desiccators [8]. A schematic diagram of SB synthesis is illustrated in Fig. 1.

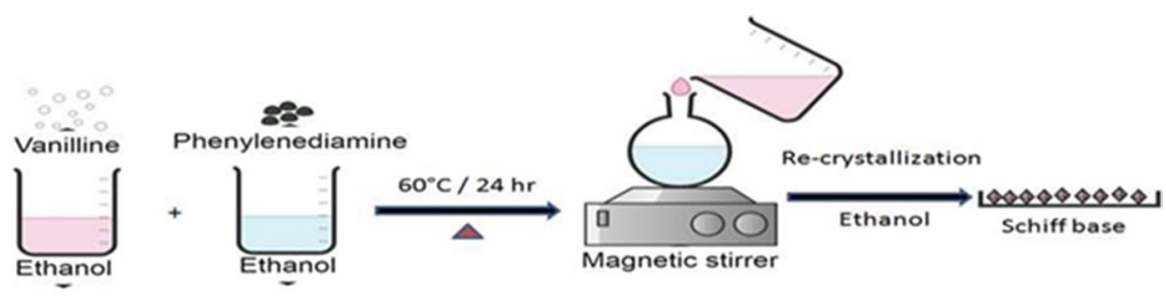

Fig. 1 Schematic diagram of SB synthesis 


\section{Yield calculation}

The percentage yield of the reaction is defined as the percentage of a product obtained compared to the predicted yield calculated from the balanced Eq. 1 .

Yield percentage $=100 \times$ Actual yield $/$ predicted theoretical yield

\section{Fabrication of PLA-p-SB bio-composite films}

PLA granules were dried in a hot air oven at $60{ }^{\circ} \mathrm{C}$ for $24 \mathrm{~h}$ to remove any moisture present on its surface and later cryogenically milled into powder form. $2 \mathrm{~g}$ of PLA powder was dissolved in DCM solvent with continuous stirring until the PLA powder dissolves to form a transparent solution at room temperature. Previously prepared p-SB complexes (1,3, and $5 \mathrm{wt} \%$ ) were mixed with a PLA solution with several concentrations and kept under ultra-sonication for an hour until the solution became homogeneous. The PLA-p-SB bio-composite solution was then poured into a Petri dish to get a film (illustrated in Fig. 2) after $24 \mathrm{~h}$ at room temperature $\left(30{ }^{\circ} \mathrm{C}\right)$. The resulting bio-composite film was vacuum dried for $24 \mathrm{~h}$ to remove any solvent present.

\section{Fourier transform-infrared spectroscopy (FT-IR)}

FT-IR spectra were obtained using Bruker, VERTEX 80 Series-FT-IR Spectrometers. A small quantity of PLA film sample was mixed with Potassium bromide $(\mathrm{KBr})$ and compressed to get the pellets. These pellets were scanned for FT-IR in transmission mode, in the spectral frequency range of 4000 to $400 \mathrm{~cm}^{-1}$. The same procedure was followed for PLA-p-SB film samples.

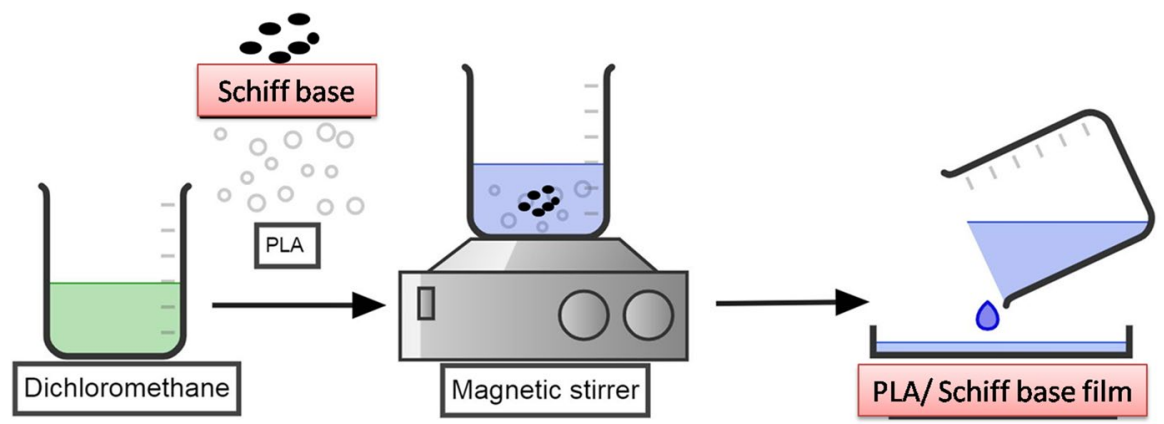

Fig. 2 Schematic diagram of PLA-p-SB bio-composite films sample preparation 


\section{Scanning electron microscopy (SEM)}

Scanning electron microscope (LEO 1445VP) characterized the surface morphology of PLA and PLA-p-SB bio-composite film samples of PLA-p-SB (1\%) and PLA-p$\mathrm{SB}(3 \%)$. The film samples were cut into $5 \times 5 \mathrm{~mm}$ size using a scalper for surface texture analysis at an accelerating voltage of $15 \mathrm{kV}$.

\section{Differential scanning calorimetry (DSC)}

DSC analysis was carried out in NETZSCH DSC-214 Polyma system at $10{ }^{\circ} \mathrm{C} \mathrm{min}^{-1}$ using nitrogen as purging gas. The calibration of the instrument was set with indium. DSC thermal analysis conducted for both virgin PLA and PLA-p-SB bio-composite film samples. The glass transition temperature $\left(T_{\mathrm{g}}\right)$, specific heat $\left(\Delta C_{\mathrm{p}}\right)$, cold crystallization temperature $\left(T_{\mathrm{c}}\right)$, and melting enthalpy $\left(\Delta \mathrm{H}_{\mathrm{m}}\right)$ were calculated. The degree of crystallinity $\left(\chi_{\mathrm{c}}\right)$ values for neat PLA and PLA-p-SB bio-composite films were calculated using Eq. (2).

$$
\text { Degree of crystallinity } \chi_{c}=\left(\Delta H_{c}+\Delta H_{m}\right) /\left(\Delta H_{o}\right) \times 100
$$

where $\Delta H_{\mathrm{c}}$ and $\Delta \mathrm{H}_{\mathrm{m}}$ are the enthalpies of cold crystallization and the enthalpy of melting, respectively. $\Delta \mathrm{H}_{\mathrm{o}}$ considered as the enthalpy of $100 \%$ crystalline PLLA is $93.6 \mathrm{~J} . \mathrm{g}^{-1}$.

\section{Tensile strength and elongation at break}

Tensile strength measures the highest amount of stress a material can withstand without any deformity from its original state. PLA-p-SB bio-composite film samples were cut into strips with dimensions $150 \mathrm{~mm}$ length $\times 25 \mathrm{~mm}$ width. The mechanical properties of bio-composite films were tested as per ASTM D882 using an Instron Mechanical Tester (Model 5564) at a $5 \mathrm{~mm} / \mathrm{min}$ testing speed. The elongation at break was calculated by dividing initial to final gap multiplied by 100 before it breaks; elongation at break expressed in $\mathrm{mm}$. The percentage of elongation was calculated using Eq. (3).

Percent elongation $=($ Elongation at rupture $) /($ Initial gauge length $) \times 100$.

\section{Contact angle}

Contact angle was measured for individual bio-composites films. Approximately $10 \mu \mathrm{L}$ of a water droplet was placed on the neat PLA and PLA-p-SB films, and the contact angle was measured using contact angle analyzer. The average value was calculated by taking ten different measurements. 


\section{Antifungal activity}

The antifungal activity was performed for neat PLA and PLA-p-SB bio-composite film samples using bread slices as a carrier for fungal growth. The sliced bread pieces were water sprayed, making them moist, enabling the fungal growth. It was then wrapped in an aluminum foil and closed for 3 days. After 3 days, the PLA films and PLA-p-SB (1\%) film samples were placed over the bread slices individually and wrapped well in an aluminum foil at $30{ }^{\circ} \mathrm{C}$ with $\mathrm{RH}$ of $75 \%$. The samples were stored carefully and regularly monitored for a period of one week.

\section{Antibacterial studies}

Agar well diffusion method was used to evaluate the test samples antimicrobial activity. For reference, Gentamycin, an antibiotic agent, was added (40 $\mu \mathrm{l}$ from $4 \mathrm{mg} / \mathrm{ml}$ stock) in the positive well (+) and the negative well (-) with the solvent dimethyl sulfoxide (DMSO) used for the sample dilution. The plates were incubated for $24 \mathrm{~h}$ at $36{ }^{\circ} \mathrm{C} \pm 1{ }^{\circ} \mathrm{C}$, under aerobic conditions. Hence, after incubation, the plates were observed for the zone of bacterial growth inhibition (measured in $\mathrm{mm}$ ) around the wells.

\section{Coating of paper samples}

Kraft paper substrates were cut into $(230 \times 280) \mathrm{mm}$ sized sheets and were placed on a leveled surface table to obtain a uniform coating. A bar-coater was used to apply the coating of PLA, and PLA-p-SB on Kraft paper substrates that were allowed to dry at $30{ }^{\circ} \mathrm{C}$ for $24 \mathrm{~h}$ inside a vacuum oven under $100 \mathrm{~m}$.bar pressure. Furthermore, these samples were dried at $90^{\circ} \mathrm{C}$ for $24 \mathrm{~h}$.

\section{Coated paper conditioning}

The coated Kraft paper samples along with the reference (i.e., uncoated Kraft paper) were conditioned in a humidity chamber maintained with $75 \%$ relative humidity at $30{ }^{\circ} \mathrm{C}$ for $24 \mathrm{~h}$.

\section{Air resistance by Gurley method}

Air resistance was performed as per ASTM D726-94 method. The neat PLA and PLA-p-SB solution coated Kraft paper samples were cut and affixed in the Gurley densometer then subjected to air pressure. Time required to pass through 
$100 \mathrm{cc}$ of air in the paper was checked using the Gurley apparatus. The results are expressed in s/100 cc unit.

\section{Surface roughness}

Surface roughness values were measured for neat PLA and PLA-p-SB solution coated Kraft paper samples with the surface roughness meter (Mitutoyo Corp, Japan).

\section{Oil-grease resistance}

Oil-grease resistance Kit test was performed with ASTM F119 method. One drop of the KIT reagent (castor oil with toluene and n-heptane solvents) was placed on the coated paper sample and after $15 \mathrm{~s}$ the KIT solution was wiped off using cotton. The darkening or penetration of the solution into the paper sample was examined by changing the number of KIT solutions.

\section{Heat seal strength}

Heat seal strength was measured as per ASTM F88 method. The coated paper samples were cut in form of strips with dimensions $15 \mathrm{~mm}$ width $\times 150 \mathrm{~mm}$ length and the strip was cut into two pieces, and the two halves were heat-sealed at $150{ }^{\circ} \mathrm{C}$ for 1 min using a bar sealer and the paper samples were cooled to room temperature. The heat seal strength was measured using universal testing machine (UTM, Shimadzu).

\section{Water absorption test: Cobb test}

The water absorption of the uncoated Kraft paper, neat PLA coated and PLA-p-SBcoated paper samples was measured using Cobb apparatus in accordance with the standards TAPPI T441 protocol for $30 \mathrm{~s}$. The results were expressed in units $\left(\mathrm{g} / \mathrm{m}^{2}\right)$.

Weight of water absorption $\left(\mathrm{g} \mathrm{m}^{-2}\right)=\left(w_{2}-w_{1}\right) \times 100$

$w_{1}=$ initial weight of treated papers.

$w_{2}=$ final weight of treated paper after Cobb test.

\section{Results and discussion}

\section{The concept}

The FT-IR spectrum of synthesized p-SB complexes is shown in Fig. 3a. The vibrational stretching frequencies appeared for ortho, meta, and para isomers confirmed the formation of SB compounds. The IR data are shown in Table 1 [9]. The product 

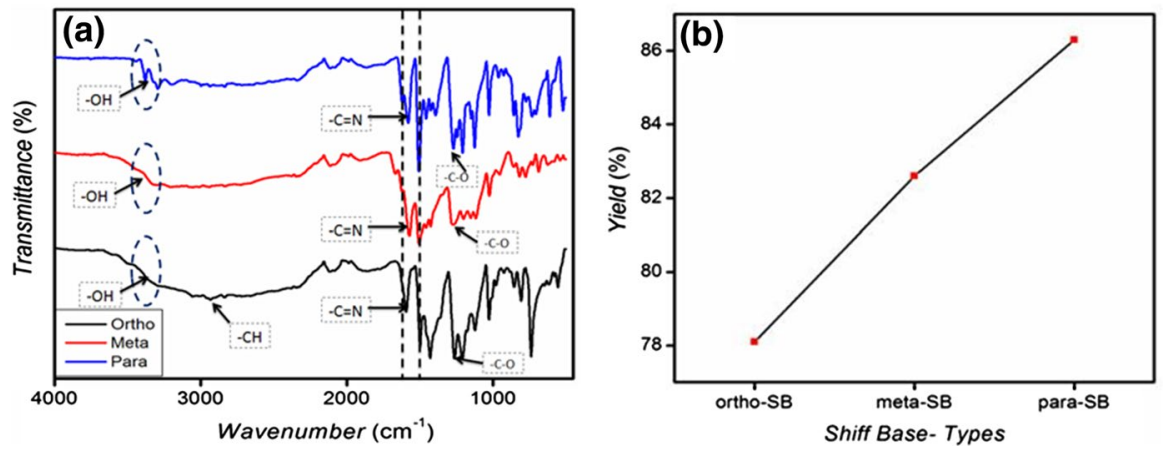

Fig. 3 FT-IR details of a Schiff's base isomers and $\mathbf{b}$ yield percentage

Table 1 IR absorption bands of Schiff's base complexes

\begin{tabular}{lllllll}
\hline Schiff base & $\begin{array}{l}\mathrm{C}=\mathrm{N} \\
(\text { Stretch) } \\
\mathrm{cm}^{-1}\end{array}$ & $\begin{array}{l}\mathrm{C}=\mathrm{C} \text { (Aromatic) } \\
\mathrm{cm}^{-1}\end{array}$ & $\begin{array}{l}\mathrm{C}-\mathrm{O} \\
(\text { Stretch) } \\
\mathrm{cm}^{-1}\end{array}$ & $\mathrm{O}-\mathrm{H}$ (Stretch) $\mathrm{cm}^{-1}$ & $\begin{array}{l}\mathrm{C}-\mathrm{N} \\
(\text { Aromatic) } \\
\mathrm{cm}^{-1}\end{array}$ & $\begin{array}{l}\mathrm{C}-\mathrm{H} \\
(\text { Stretch) } \\
\mathrm{cm}^{-1}\end{array}$ \\
\hline $\mathrm{o}-\mathrm{Sb}$ & 1613 & 1429 & 1263 & $\begin{array}{l}2933 \\
(\text { weak })\end{array}$ & 1266 & 2936 \\
$\mathrm{~m}-\mathrm{Sb}$ & 1606 & 1426 & 1266 & $\begin{array}{l}3058 \\
(\text { weak })\end{array}$ & 1270 & 2939 \\
$\mathrm{p}-\mathrm{Sb}$ & 1646 & 1457 & 1280 & $\begin{array}{l}3378 \\
\text { (strong) }\end{array}$ & 1320 & 2996 \\
\hline
\end{tabular}

obtained after the reaction was washed well with chloroform, dried in an oven at $60{ }^{\circ} \mathrm{C}$, and weighed in the weighing machine. Para Schiff's base (p-SB) shows a higher percentage of yield (87\%) than o-SB and m-SB, as shown in Fig. $3 \mathrm{~b}$.

Interestingly, the para isomer was found to exhibit the highest antioxidant activity among the three isomers. The reason behind it may be due to the strong $\mathrm{O}-\mathrm{H}$ stretching vibration of the para isomer at $3378 \mathrm{~cm}^{-1}$, formed an intermolecular hydrogen bonding. In contrast to this observation, Ortho and Meta isomers showed a weak O-H stretching at $2933 \mathrm{~cm}^{-1}$ and $3058 \mathrm{~cm}^{-1}$, which seemed to have formed an intra-molecular hydrogen bonding [10]. Additionally, the para isomer was found to have the highest number of resonance structures and thus experienced the lowest steric repulsion is illustrated in Fig. 4. Accordingly, the p-SB complex was chosen for the modification of PLA.

\section{FT-IR interaction between PLA and SB}

The FT-IR spectra of neat PLA and PLA-p-SB (1\%) film samples are depicted in Fig. 5. The characteristics peaks of neat PLA were noticed at $1750 \mathrm{~cm}^{-1}$, $1181 \mathrm{~cm}^{-1}, 1079 \mathrm{~cm}^{-1}, 1452 \mathrm{~cm}^{-1}, 1360 \mathrm{~cm}^{-1}, 2944 \mathrm{~cm}^{-1}, 2995 \mathrm{~cm}^{-1}, 867 \mathrm{~cm}^{-1}$, $753 \mathrm{~cm}^{-1}$ corresponding's to $\mathrm{C}=\mathrm{O}$ carbonyl stretching, $\mathrm{C}-\mathrm{O}-\mathrm{C}$ ether asymmetric stretching, $\mathrm{C}-\mathrm{O}-\mathrm{C}$ ether symmetric stretching, $\mathrm{CH}_{3}$ methyl asymmetric stretching, 


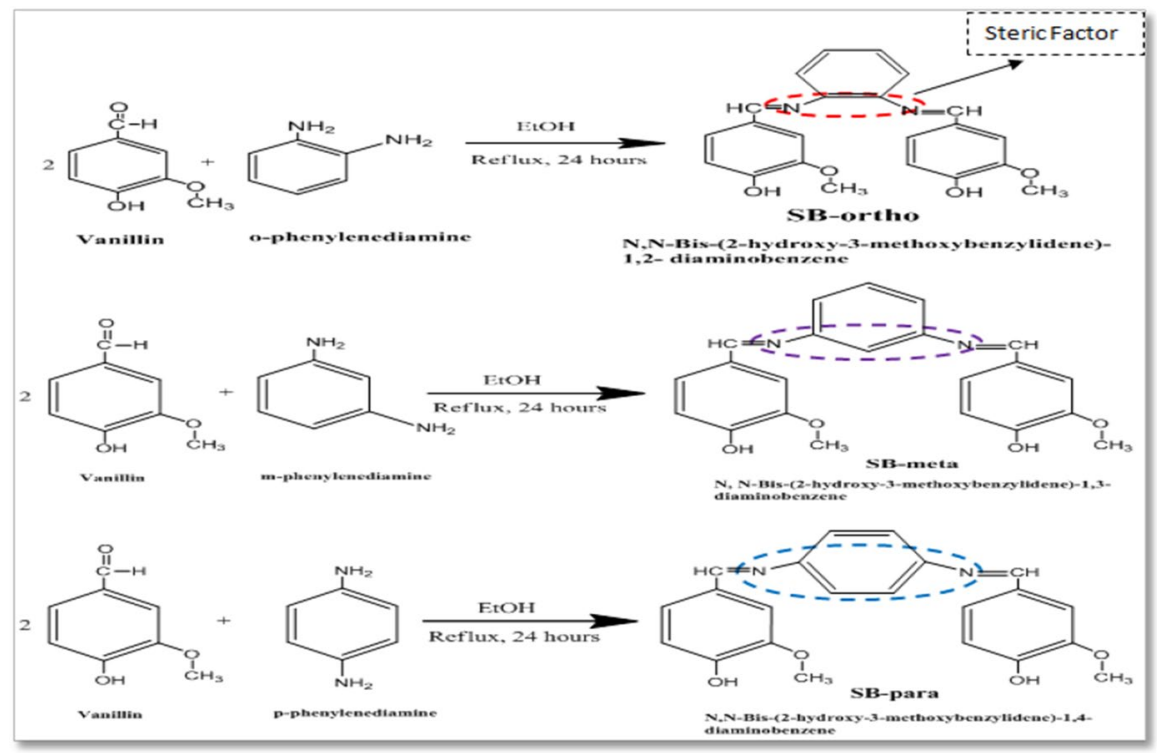

Fig. 4 Steric factor of Schiff's base isomers

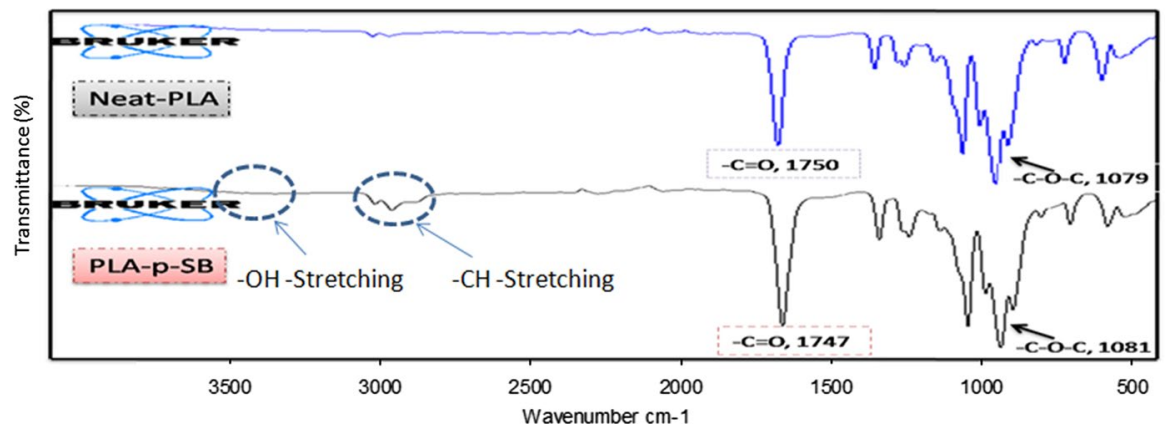

Fig. 5 FT-IR details of neat PLA and PLA-p-SB

$\mathrm{CH}_{3}$ group $\mathrm{CH}$ bending, $\mathrm{CH}$ asymmetric vibration, $\mathrm{CH}$ symmetric stretching vibration, amorphous and crystalline phases of PLA, respectively [11].

We have analyzed the effect of SB addition into the PLA matrix to understand its modifications in chemical structure and flexibility caused due to their interactions. A similar type of work was reported by Tawakkal et al. [12]. The FT-IR spectra of the PLA-p-SB obtained with the characteristic's peaks at $1747 \mathrm{~cm}^{-1}$, $1181 \mathrm{~cm}^{-1}$ correspond to $\mathrm{C}=\mathrm{O}$ stretching, $\mathrm{C}-\mathrm{O}-\mathrm{C}$ asymmetric stretching, respectively. In comparison with the neat PLA, the PLA-p-SB blend showed a band position shift from 1750 to $1747 \mathrm{~cm}^{-1}$, which corresponds to $\mathrm{C}=\mathrm{O}$ carbonyl group stretching vibration. This shift clearly indicating the $\mathrm{C}=\mathrm{O}$ carbonyl group of the PLA involved in the interactions with $\mathrm{p}-\mathrm{SB}-\mathrm{OH}$ group through hydrogen bonding 


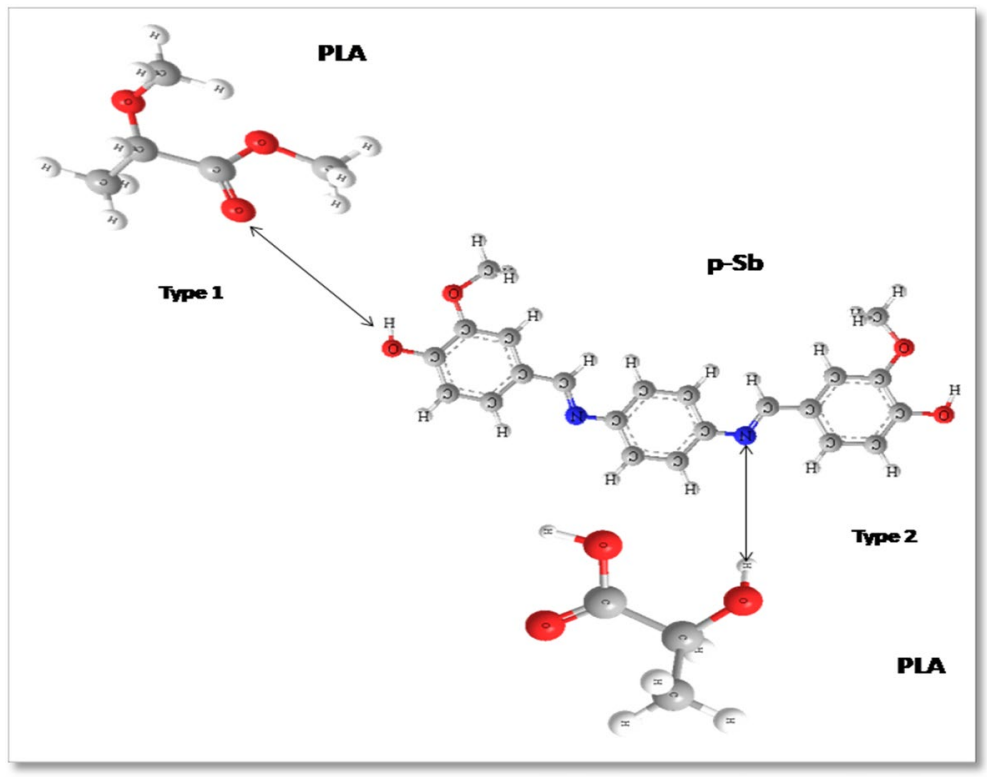

Fig. 6 Possible interactions between PLA and p-SB

(depicted in Fig. 6). The successful dispersion of p-SB into PLA has led to an increased toughness due to this strong intermolecular hydrogen bonding in it [12]. Thus, incorporating a p-SB complex in PLA enhanced its toughness through type 1 and type 2 interactions shown in Fig. 6. The neat PLA formed a brittle film over the Kraft paper substrate, which indicates the existence of cracks and delamination after the coating was applied and dried on it. It was this main drawback that restricts the usage of neat PLA in coating industries. However, by modifying PLA with p-SB, the brittleness of PLA was eliminated considerably, thereby making it ideally suitable for industrial use.

\section{Morphological analysis}

On observation, it was understood that the interaction between PLA and $1 \%$ of p-SB enabled a proper dispersion to form a uniform film (shown in Fig. 7a) over the Kraft paper surface to impart its increased toughness. However, the incorporation of $3 \% \mathrm{p}$-SB in PLA formed agglomerate on the surface, which could be visible from Fig. $7 \mathrm{~b}$ that illustrates the openings of pores that were clearly visible on the surface PLA-p-SB (3\%) film [6].

\section{Differential scanning calorimetry (DSC)}

Figure 8 shows the DSC thermograms of neat PLA and PLA-p-SB (1\%) films, respectively. Totally, three thermal transitions could be found using DSC; they are 

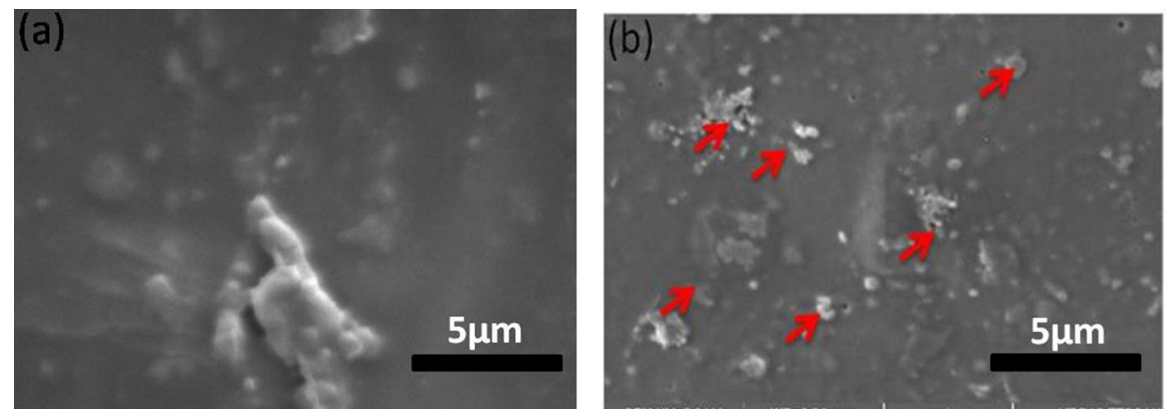

Fig. 7 SEM images of a $5 \mu$ m PLA-p-SB (1\%) film and b $5 \mu$ m PLA-p-SB (3\%) film

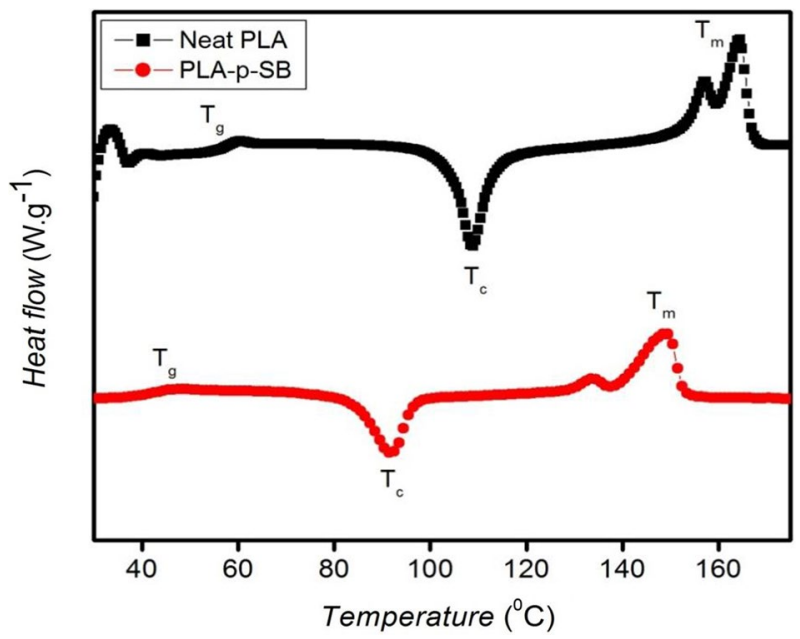

Fig. 8 DSC images of neat PLA and PLA-p-SB

namely (1) glass transition temperature $\left(T_{g}\right)$, (2) exothermic crystallization $\left(T_{c}\right)$, and (3) endothermic melting $\left(\mathrm{T}_{\mathrm{m}}\right)$ processes. The DSC of neat PLA showed $\mathrm{T}_{\mathrm{g}}$ at $55^{\circ} \mathrm{C}$, with the corresponding $\Delta \mathrm{C}_{\mathrm{p}}$ value of $0.042 \mathrm{~J} . \mathrm{K}^{-1} \cdot \mathrm{g}^{-1}$. The melting peak was noticed at $156.6^{\circ} \mathrm{C}$, with a similar melting enthalpy of $30.92{\mathrm{~J} . \mathrm{g}^{-1}}^{-1}$ The $33 \%$ crystallinity exhibited by neat PLA accounts for its semicrystalline nature [13-15].

It was interesting to observe that the PLA-p-SB film shows $T_{\mathrm{g}}$ at $45{ }^{\circ} \mathrm{C}$, which was $10^{\circ} \mathrm{C}$ lower than the $T_{\mathrm{g}}$ of neat PLA. This significant reduction in $T_{\mathrm{g}}$ resulted in better flexibility imparted by PLA-p-SB than neat PLA. We assume there were free volume patches present in the PLA-p-SB that can be understood according to the free volume theory [16]. Hence, this free volume plasticizes the polymer and causes it to undergo a glassy to rubbery transition [16]. This plasticizing effect achieved via p-SB due to the free volume patches present in the PLA-p-SB blend, thus resulting in lower Tg. Similarly, the PLA-p-SB's melting and cold crystallization temperature found decreased in comparison with neat PLA. 


\section{Mechanical strength}

The tensile strength and elongation at break values of neat PLA and PLA-p-SB films with varying weight percentages are shown in Fig. 9a and b, respectively. The highest value was recorded at $1 \%$ of PLA-p-SB film (3.8 MPa), which slowly reduced to $2.3 \mathrm{MPa}$ at $5 \%$ of the PLA-p-SB bio-composite mixture, causing brittleness due to the higher percentage loading of filler. On increasing the p-SB filler content in PLA, there was a reduction in tensile strength. It might be due to the poor dispersity of p-SB filler into the PLA matrix, which led to the agglomeration at higher filler loading. Similarly, in elongation at break, the highest value was recorded at $3 \%$ of PLA-p-SB film (3.9\%). Beyond which, there was a reduction in both tensile strength and elongation values. Such decreasing elongation value with an increasing filler content was reported by Atuanya et al. and Sanadi et al. [17, 18]. Hence, a lower filler content in PLA encouraged a homogenous dispersion, which led to increased stiffness and toughness in the PLA-p-SB (1\%) composite film [19]. In contrast, the higher filler loading in PLA led to agglomeration and subsequently decreased stiffness and toughness of the resulting films.

\section{Contact angle}

The incorporation of $\mathrm{p}-\mathrm{SB}$ in PLA improved the surface hydrophobicity of PLA and thus contact angle values. The measured values of contact angles for neat PLA, PLA-p-SB (1\%, 3\%, and 5\%) films using water as a medium can be observed from Fig. 10a. It was interesting to observe that the contact angle value of the neat PLA matrix increased by $8^{\circ}$ due to the incorporation of $1 \%$ p-SB filler content in it. However, further increasing p-SB filler concentration beyond $1 \%$ did not enhance the composite film's hydrophobicity. The decrease in hydrophobicity might be due to the difference in composite film's chemical properties and surface morphology [20]. We understand there were free volume patches present in the PLA-p-SB film through which the penetrant water molecules invade, when made to contact thermodynamically. Furthermore, the fraction volume of polymer in the swollen state
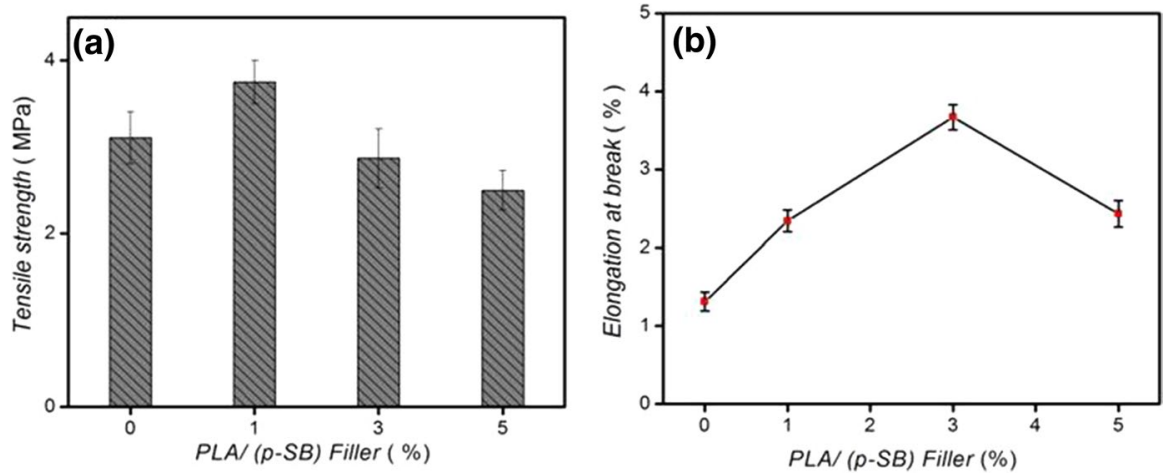

Fig. 9 a Tensile strength (MPa) and b elongation at break (\%) 

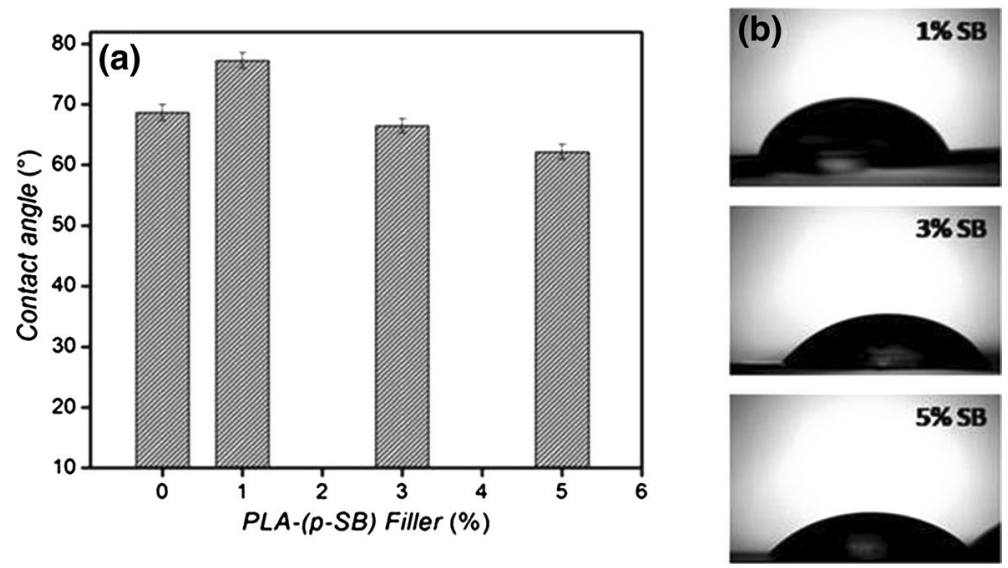

Fig. 10 a Contact angle values and $\mathbf{b}$ contact angle images

implies the amount of water that can be infiltrated into a polymer matrix. The volume fraction of PLA-p-SB (3\%) decreased with an increase in chain length of SB, which, in turn, increases swollen polymer volume. The reason being the distance between two interacting points increases in the case of PLA-p-SB (3\%) and the free volume available also increases accordingly. Hence, the volume fraction of polymer decreases. In contrast, the distance between two interacting points decreases in the case of PLA-p-SB (1\%) and the free volume available also decreases when compared to PLA-p-SB (3\%). Hence, the volume fraction of polymer increases. Accordingly, the 1\% PLA-p-SB film had good dispersion behavior that resulted in increased toughness and stiffness. But on increasing the p-SB filler content, agglomeration of particle occurred, which prevented and weakened the interaction of $\mathrm{p}-\mathrm{SB}$ with PLA. It consequently led to the formation of a porous layer on the PLA-p-SB (3\%) film surface, which accounts for its reduced contact angle value as well. The contact angle images of different bio-composite surfaces are shown in Fig. 10b.

\section{Antifungal studies}

Turalija et al. [21] had reported a low antifungal behavior of PLA in his discussions. However, the incorporation of p-SB (being an excellent antibacterial and antifungal agent) [22] into the PLA matrix improved the antifungal behavior of PLA significantly. Rarima et al. [6] developed porous PLA membranes, typically for wound dressing using zinc oxide and SB.

In our case, neat PLA and PLA-p-SB (1\%) film samples $(2 \mathrm{~cm} \times 1 \mathrm{~cm})$ were tested after in vitro tests by studying the fungal growth inhibition in an in situ environment. It is done by using an un-inoculated bread carrier to elucidate their antifungal properties. The images are shown in Fig. 11a and b, respectively. When the films were removed from bread slices, the fungal growth was observed in both the films. However, the fungal growth occurred earlier in neat PLA film as the bread formulation did not contain any preservatives. At the same time, PLA-p-SB film 

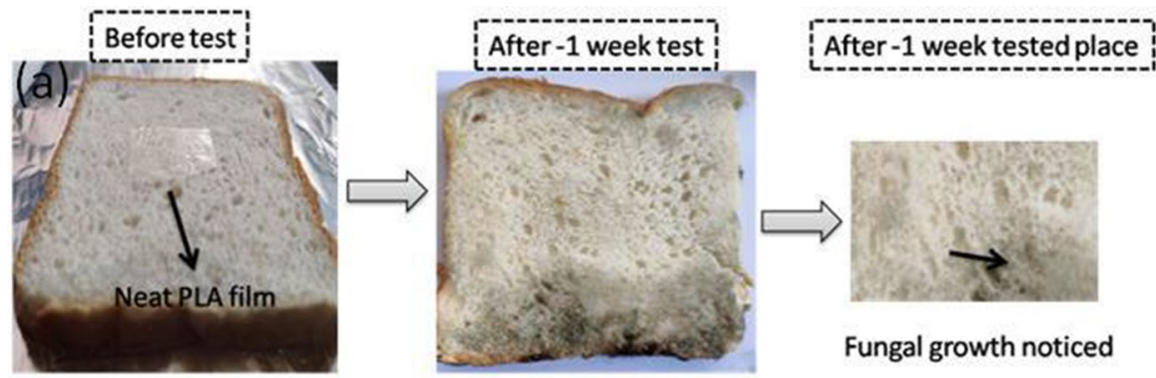

Fungal growth noticed
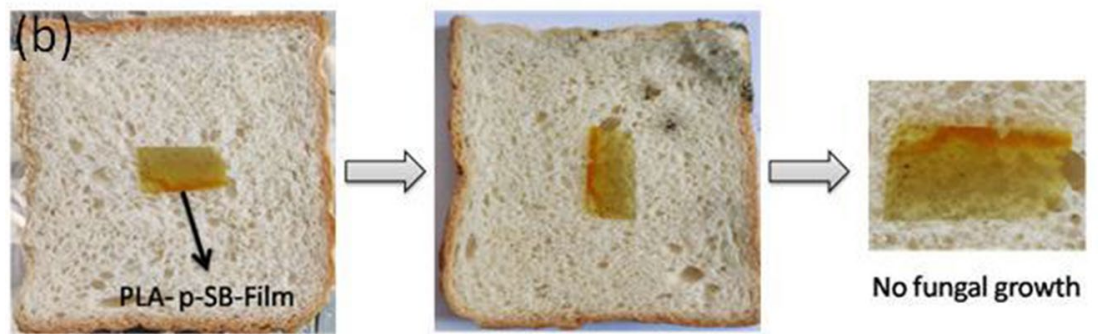

No fungal growth

Fig. 11 Growth of natural fungi on un-inoculated bread: a neat PLA and b PLA-p-SB (1\%)

showed excellent antifungal activity by delaying the fungal growth, and the values are reported in Table 2. As reported, the water activity of bread was around 0.95 [23]. The humidity created in the internal atmosphere activated the release of antimicrobial compounds in the PLA-p-SB film, which offered higher resistance against fungal growth [24]. The results indicate that the antimicrobial effect of PLA-p-SB film was fungistatic.

\section{Antibacterial studies}

Agar well diffusion method evaluated the test samples antimicrobial activity, and the test results are given in Table 3 [25]. The neat PLA was found to be completely inert against both $\mathrm{S}$. aureus and $\mathrm{P}$. aeruginosa bacteria, as shown in Fig. 12a and c, respectively. But higher inhibition zone toward both bacteria, $S$. aureus $(11 \mathrm{~mm}, 13 \mathrm{~mm})$ and $P$. aeruginosa $(11 \mathrm{~mm}, 15 \mathrm{~mm})$, in the case of

Table 2 Evolution of fungal growth on bread slices

\begin{tabular}{|c|c|c|c|c|c|}
\hline \multirow[t]{2}{*}{ Types of film } & \multirow[t]{2}{*}{ Fungi } & \multirow{2}{*}{$\begin{array}{l}\text { Growth } \\
\text { Delay }^{*} \\
\text { (days) }\end{array}$} & \multicolumn{3}{|c|}{ Fungal growth } \\
\hline & & & Day 7 & Day 14 & Day 21 \\
\hline Neat PLA & Naturally present fungi & 3 & + & ++ & +++ \\
\hline PLA-p-SB ( $1 \%)$ & Naturally present Fungi & 5 & + & + & + \\
\hline
\end{tabular}

\footnotetext{
*Number of days until visible of fungal growth, - absence of fungal growth, + fungal growth on $<25 \%$ of surface, ++ fungal growth on $50 \%$ of surface, +++ fungal growth $>75 \%$ of surface
} 
Table 3 Report on antibacterial studies

\begin{tabular}{|c|c|c|c|c|c|c|}
\hline \multirow[t]{2}{*}{ S1. no. } & \multirow[t]{2}{*}{ Sample } & \multirow[t]{2}{*}{ Test organism } & \multicolumn{4}{|c|}{ Zone of inhibition (mm) } \\
\hline & & & $\begin{array}{l}\text { Gentamycin } \\
(+) 160 \\
\text { mcg }\end{array}$ & $\begin{array}{l}\text { The solvent used } \\
\text { (DMSO) for sample } \\
\text { dilution }(-)\end{array}$ & Trail 1 & Trail 2 \\
\hline A & Neat PLA & Staphylococcus aureus & 23 & - & - & - \\
\hline B & PLA-p-SB & Staphylococcus aureus & 23 & - & 11 & 13 \\
\hline $\mathrm{C}$ & Neat PLA & $\begin{array}{l}\text { Pseudomonas aerugi- } \\
\quad \text { nosa }\end{array}$ & 28 & - & - & - \\
\hline $\mathrm{D}$ & PLA-p-SB & $\begin{array}{l}\text { Pseudomonas aerugi- } \\
\quad \text { nosa }\end{array}$ & 28 & - & 11 & 15 \\
\hline
\end{tabular}

\section{(a)}

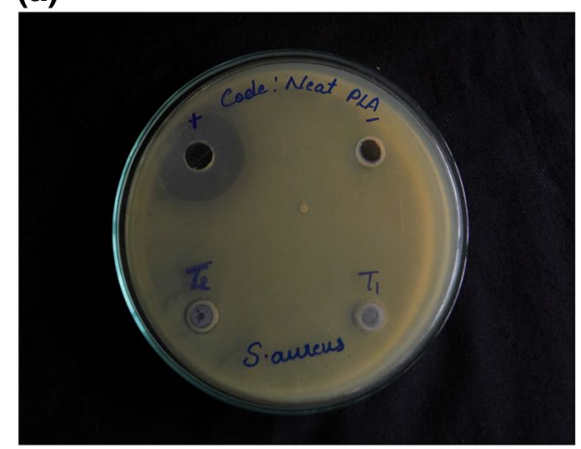

(c)

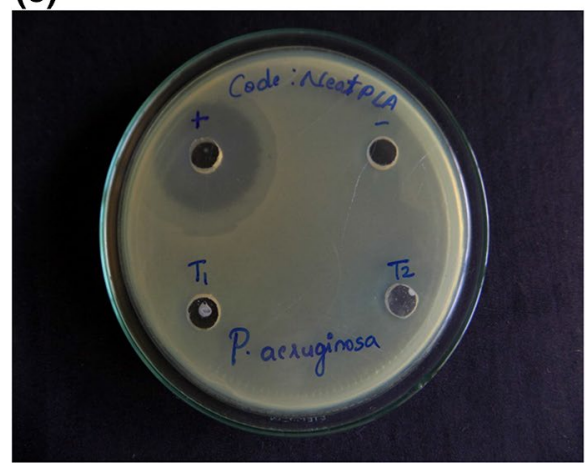

(b)

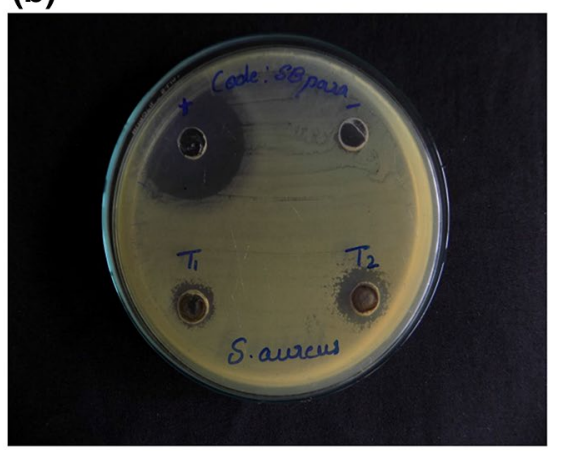

(d)

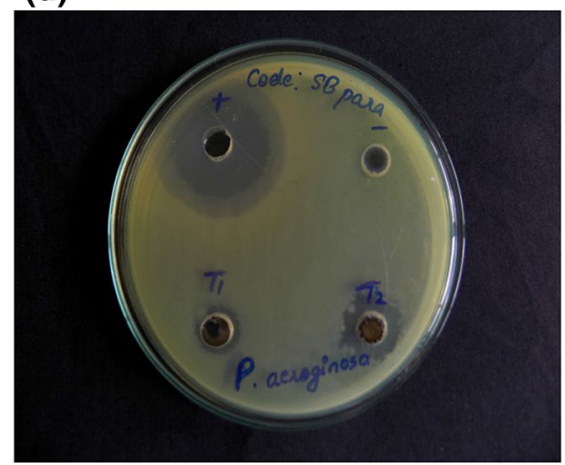

Fig. 12 Resistance study of a PLA against $S$. aureus, b PLA-p-SB against $S$. aureus, c PLA against Aeruginosa, and d PLA-p-SB against Aeruginosa

PLA-p-SB films, is shown in Fig. 12b and d, respectively. Since p-SB compounds posses excellent antimicrobial properties, they seem to have killed the bacteria plasma membrane present around it. Thus, by incorporating p-SB into the PLA matrix, the antibacterial properties of PLA could be improved significantly. 


\section{Kraft paper coatings}

\section{Paper coating weight and thickness}

The coating weight of neat PLA and PLA-p-SB over the Kraft paper was obtained after solvent evaporation by keeping the coated samples at $90{ }^{\circ} \mathrm{C}$ in an oven about an hour. The coated paper samples visually looked smooth, and the coatings had adequate affinity with the Kraft paper. Since PLA-4060D is semicrystalline, it is prone to crystallization and delamination. This is one of the main reasons why we attempted to modify the neat PLA with p-SB so as to improve its coating properties besides antimicrobial properties [12]. A uniform film was obtained by coating the PLA-p-SB polymer solution over the Kraft paper, whose thickness was found to be $1.52 \pm 0.08 \mathrm{~g} \cdot \mathrm{m}^{-2}$.

\section{Surface roughness}

It is an essential parameter for measuring the surface texture, including roughness, waviness. Figure 13 a shows that an addition of $1 \%$ p-SB into the PLA matrix did not even decrease the smoothness of PLA paper coating. But on increasing the p-SB concentration, surface roughness changes due to particles agglomeration occurred on the Kraft paper's surface [26].

\section{Heat seal strength}

The results of heat-sealing strength are shown in Fig. 13b. The data indicate 1\% loading of $\mathrm{p}$-SB into the PLA matrix did not reduce the heat-sealing strength of PLA coated paper. On the other hand, increasing p-SB filler content in PLA formed uneven/incomplete layers on Kraft paper's surface, which caused a decrease in heat-sealing strength values [27].

\section{Air resistance}

The air porosity values tend to decrease with an increase in p-SB filler content in the PLA matrix. These results conjecture that after solvent evaporation, PLA and p-SB filler occupy the pores on the surface by forming a micro dimple over the Kraft paper. It drops the air porosity values shown in Fig. 13c [26].

\section{Oil and grease resistance}

Oil and grease resistance play a vital role in packaging products that contain oil and fats. In this work, $1 \%$ p-SB loaded PLA composite favored the oil and grease resistance behavior of Kraft paper shown in Fig. 13d. Further increase in filler content led to a highly porous structure as most of the components diffused 

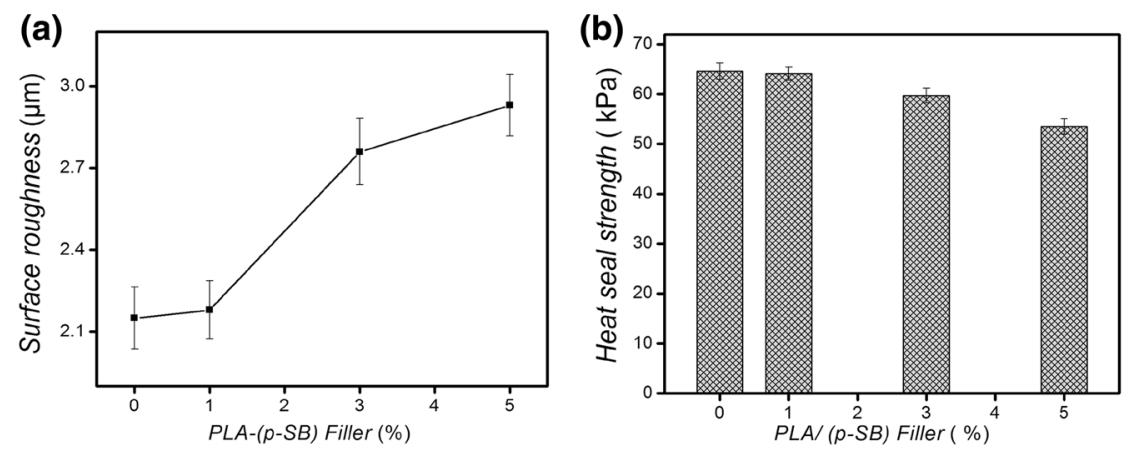

(c)

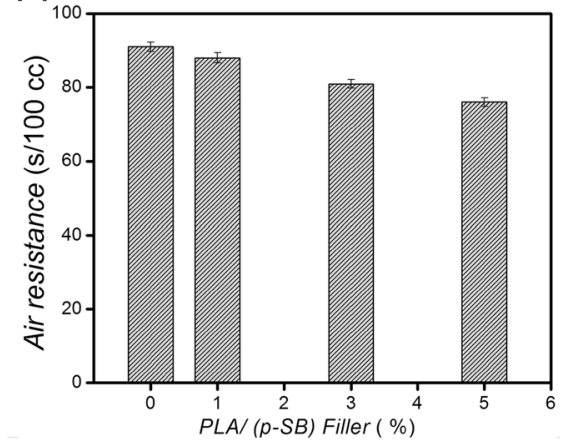

(d)

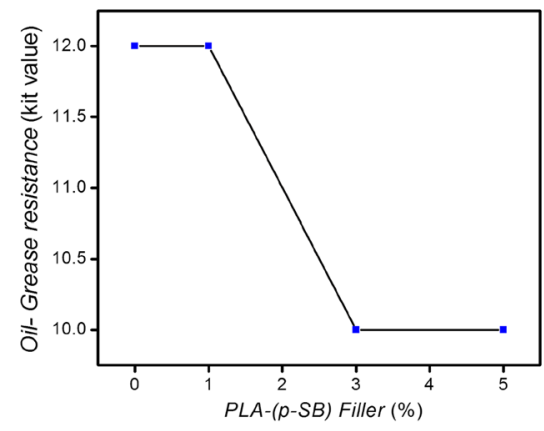

(e)

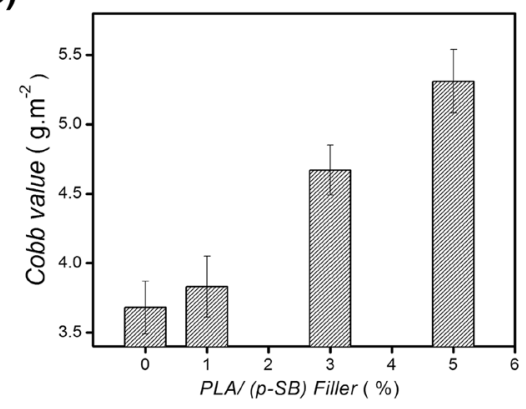

(f)

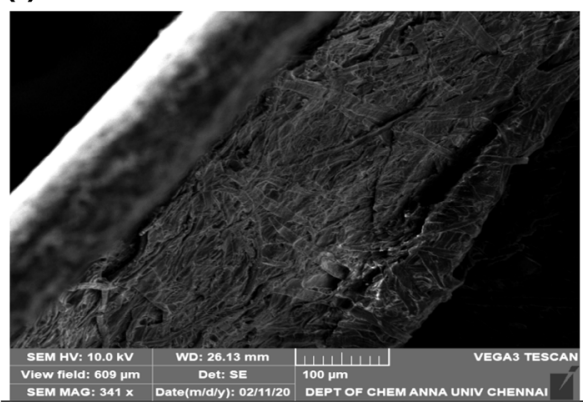

Fig. 13 a Surface roughness, b heat seal strength, c air resistance, d oil-grease resistance, e Cobb's test, and $\mathbf{f}$ cross-sectional SEM image of PLA-p-SB-coated Kraft paper

through the bulk of paper instead of forming the coating layer over its surface [28, 29].

\section{Cobb's test}

A trend of increased Cobb's value observed by increasing the p-SB content into the PLA matrix is shown in Fig. 13e. As discussed before, 1\% PLA-p-SB film had good dispersion behavior, which results in increased toughness and better adhesion on Kraft 
paper than neat PLA. However, on increasing the p-SB filler particle, agglomeration occurred, which led to pores formation on the Kraft paper surface, which in turn increased the water absorption behavior.

\section{Cross-sectional SEM}

The cross-sectional views of the PLA and PLA-p-SB-coated Kraft paper samples confirm the firm adherence of p-SB incorporated PLA over its surface. TA simple and straight forward solution coating method was adopted for this study. The solvent vehicle carries the bio-polymer composite (PLA-p-SB) to the paper surface effectively. It gets evaporated later to have left a continuous film over the Kraft paper, as shown in Fig. 13f.

\section{Conclusions}

The study's prime objective is to fabricate a p-SB reinforced PLA bio-composite film that can impart better barrier and antifungal properties than neat PLA. Accordingly, we have successfully optimized the concentration of p-SB in PLA-p-SB blend as 1\%, which could be used for active packaging applications. SB synthesized from paraphenylenediamine was the best in yield due to its reactivity, intermolecular hydrogen bonding, stability, and minimum steric hindrance effect. Furthermore, the modification of PLA with p-SB was confirmed by FT-IR. SEM studies indicated strong interfacial interactions between the PLA and p-SB that reduced the brittleness and improved the antimicrobial activity of PLA. The DSC analysis ascertained an increased blend compatibility and flexibility in PLA-p-SB (1\%) combination. Accordingly, the optimized PLA-p-SB (1\%) composition coated on Kraft paper showed better adhesion properties than the neat PLA film. Hence, we conclude that this study could certainly prove the importance of bio-based polymer as alternative packing material to replace the pollution-causing single waste synthetic-made materials. Furthermore, SB compounds could also be treated with metal complexes to show improved antimicrobial properties, which can be exploited for suitable industrial applications such as for active packaging, coated abrasive products, and corrosion prevention coatings.

Acknowledgements Instrumentation facilities provided by DST-FIST sponsored Department of Chemistry, College of Engineering, Guindy, Anna University, Chennai, is broadly acknowledged. The authors acknowledge the Department of Research \& Development, Carborundum Universal Ltd, Chennai, for their motivation and moral support for this work's DSC analysis.

\section{Declarations}

Conflict of interest The authors declare that they have no conflict of interest. 


\section{References}

1. Rick Lingle (2020). https://www.packagingdigest.com/food-safety/covid-19-raises-consumerspackaged-food-concerns. Accessed May 18, 2020

2. Obuchi S, Ogawa S (2010) Packaging and other commercial applications, Structures, Properties, Processing, Applications. John Wiley \& Sons, Inc. 24:457-467.https://doi.org/10.1002/9780470649 848.ch28

3. Joseph V (2016) Synthesis, Characterization, Crystal Structure and Biological Evaluation of Schiff Bases and Their Metal Complexes. Maharaja Sayajirao University of Baroda.http://hdl.handle.net/ $10603 / 102431$

4. Arora K, Parmar A (2015) Theoretical IR spectral and computational study of some Schiff base compounds. Int J Sci Technol 3:116

5. Soliman EA, Khalil AA, Deraz SF, El-Fawal G, Abd Elrahman S (2014) Synthesis, characterization and antibacterial activity of biodegradable films prepared from Schiff bases of zein. J Food Sci Technol 51(10):2425-2434. https://doi.org/10.1007/s13197-012-0792-y

6. Rarima R, Asaletha R, Unnikrishnan G (2018) Schiff base-assisted surface patterning of polylactide-zinc oxide films Generation characterization and biocompatibility evaluation. J Mater Sci 53:9943-9957. https://doi.org/10.1007/s10853-018-2338-9

7. Ozkoc G, Kemaloglu S (2009) Morphology, biodegradability, mechanical, and thermal properties of nanocomposite films based on PLA and plasticized PLA. J Appl Polym Sci 114:2481-2487. https:// doi.org/10.1002/app.30772

8. Bakar, Siti Najihah Abu, HadariahBahron, and KarimahKassim (2010) Synthesis and characterization of a novel Schiff base derived from 2, 4, 6-trimethyl-m-phenylenediamine with o-vanillin and its metal complexes. International Conference on Science and Social Research (CSSR 2010). IEEE, 2010

9. Bakar SN, Bahron H, Kassim K (2010) Synthesis and characterization of a novel Schiff base derived from 2, 4, 6-trimethyl-m-phenylenediamine with o-vanillin and its metal complexes. In: 2010 International Conference on Science and Social Research (CSSR 2010) IEEE, pp 463-466.https://doi. org/10.1109/cssr.2010.5773821

10. Bora G, Gogoi D, Saikia S, Pareek A, Handique JG (2019) Stannous chloride catalyzed synthesis of Schiff bases from hydroxybenzaldehydes and determination of their antioxidant activity by ABTS and DPPH assay. J Chem Sci 131:68. https://doi.org/10.1007/s12039-019-1645-2

11. Zhang J, Tsuji H, Noda I, Ozaki Y (2004) Structural changes and crystallization dynamics of poly (L-lactide) during the cold-crystallization process investigated by infrared and two-dimensional infrared correlation spectroscopy. Macromolecules 37:6433-6439. https://doi.org/10.1021/ma049 $288 \mathrm{t}$

12. Tawakkal IS, Cran MJ, Miltz J, Bigger SW (2014) A review of poly (lactic acid)-based materials for antimicrobial packaging. J Food Sci 79:1477-1490. https://doi.org/10.1111/1750-3841.12534

13. Ghosh S, Viana JC, Reis RL, Mano JF (2007) Effect of processing conditions on morphology and mechanical properties of injection molded poly (1-lactic acid). Polym Eng Sci 47:1141-1147. https://doi.org/10.1002/pen.20799

14. Ghosh S, Viana JC, Reis RL, Mano JF (2008) Oriented morphology and enhanced mechanical properties of poly (1-lactic acid) from shear controlled orientation in injection molding. Mater. Sci. Eng. A 490:81-89. https://doi.org/10.1016/j.msea.2008.01.003

15. Saiter A, Delpouve N, Dargent E, Saiter JM (2007) Cooperative rearranging region size determination by temperature modulated DSC in semi-crystalline poly (L-lactide acid). Eur. Polym. J 43:4675-4682. https://doi.org/10.1016/j.eurpolymj.2007.07.039

16. Singh TR, McCarron PA, Woolfson AD, Donnelly RF (2009) Investigation of swelling and network parameters of poly (ethylene glycol)-crosslinked poly (methyl vinyl ether-co-maleic acid) hydrogels. Eur Polym J 45:1239-1249. https://doi.org/10.1016/j.eurpolymj.2008.12.019

17. Atuanya CU, Edokpia RO, Aigbodion VS (2014) The physio-mechanical properties of recycled low density polyethylene (RLDPE)/bean pod ash particulate composites. Results Phys 4:88-95. https:// doi.org/10.1016/j.rinp.2014.05.003

18. Sanadi AR, Caulfield DF, Jacobson RE, Rowell RM (1995) Renewable agricultural fibers as reinforcing fillers in plastics: mechanical properties of kenaf fiber-polypropylene composites. Ind Eng Chem Res 34:1889-1896. https://doi.org/10.1021/ie00044a041 
19. Onuoha C, Onyemaobi OO, Anyakwo CN, Onuegbu GC (2017) Effect of filler loading and particle size on the mechanical properties of periwinkle shell filled recycled polypropylene composites. Am J Eng Res 6:72-79

20. Jose AJ, Alagar M (2015) Preparation and characterization of polysulfone-based nanocomposites. In: Manufacturing of Nanocomposites with Engineering Plastics. Elsevier, pp 31-59.https://doi.org/ 10.1016/B978-1-78242-308-9.00003-3

21. Turalija M, Bischof S, Budimir A, Gaan S (2016) Antimicrobial PLA films from environment friendly additives. Compos Part B: Eng 102:94-99. https://doi.org/10.1016/j.compositesb.2016.07. 017

22. Ronad PM, Noolvi MN, Sapkal S, Dharbhamulla S, Maddi VS (2010) Synthesis and antimicrobial activity of 7-(2-substituted phenylthiazolidinyl)-benzopyran-2-one derivatives. Euro J Med Chem 45:85-89. https://doi.org/10.1002/chin.201019126

23. Schmidt SJ, Fontana AJ (2020) Water Activity Values of Select Food Ingredients and Products. Water activity in foods: Fundamentals and applications. 573-591.https://doi.org/10.1002/ 9781118765982.app5

24. Balaguer MP, Lopez-Carballo G, Catala R, Gavara R, Hernandez-Munoz P (2013) Antifungal properties of gliadin films incorporating cinnamaldehyde and application in active food packaging of bread and cheese spread foodstuffs. Int J Food Microbiol 166:369-377. https://doi.org/10.1016/j. ijfoodmicro.2013.08.012

25. Valgas C, Souza SM, Smânia EF, Smânia A Jr (2007) Screening methods to determine antibacterial activity of natural products. Braz J Microbiol 38:369-380. https://doi.org/10.1590/S1517-83822 007000200034

26. Sundar N, Kumar A, Pavithra A, Ghosh S (2020) Studies on semi-crystalline poly lactic acid PLA as a hydrophobic coating material on kraft paper for imparting barrier properties in coated abrasive applications. Prog Org Coat 145:105682. https://doi.org/10.1016/j.porgcoat.2020.105682

27. Rhim JW, Kim JH (2009) Properties of poly (lactide)-coated paperboard for the use of 1-way paper cup. J Food Sci 74:105-111. https://doi.org/10.1111/j.1750-3841.2009.01073.x

28. Tyagi P, Hubbe MA, Lucia L, Pal L (2018) High performance nanocellulose-based composite coatings for oil and grease resistance. Cellulose 25:3377-3391. https://doi.org/10.1007/ s10570-018-1810-7

29. Ahlroos J, Alexandersson M, Grön J (1998) Influence of base paper filler content and pre-calendaring on metered film press coating-Part II: Paper and print quality. In: COATING PAPERMAKERS CONFERENCE, TAPPI PRESS 915-926

Publisher's Note Springer Nature remains neutral with regard to jurisdictional claims in published maps and institutional affiliations. 